\title{
Error Analysis in Solving Geometry Problem on Pseudo-Thinking's Students
}

\author{
Yunis Sulistyorini \\ Department of Mathematics Education \\ IKIP Budi Utomo Malang, Indonesia \\ yunis.sulistyorini@gmail.com
}

\begin{abstract}
Errors can't be avoided by learners in learning mathematics, including in problem solving. Educators should provide opportunities for learners to reflect and repair their errors. The wrong answer given by the learner may not necessarily result from the wrong thinking process. This is called pseudo thinking. Pseudo thinking in problem solving can be distinguished into pseudo-wrong and pseudo-true. The focus in this study is that pseudo-wrong students in solving geometric problems, that is, when learners answer wrongly but learners are able to explain reason properly. Pseudo thinking students make errors in understanding problem and implementing plan. Errors that occurs are misunderstanding of measure of line segment, failure to understand that triangles should be formed are a right triangle, error in applying Pythagorean theorem and the trigonometric ratios, and unable to apply triangle congruence to justify congruence of measure of two angles. Repair errors is done by implementing assimilation and accommodation process. Both of these processes involve the student's prior knowledge about concept of triangle, circle, trigonometry and Pythagorean theorem in solving problems. Through this improvement, students are able to solve problem of geometry correctly.
\end{abstract}

Keywords-error analysis, solving geometry problem, pseudothinking

\section{INTRODUCTION}

Conceptual and procedural understanding are necessary for learners in problem solving. Many domains of basic concepts and procedures must learn correctly to solve problems [4]. In fact, not all learners are able to understand and apply concepts to solve problems. Abstract mathematical concepts is one of causes of error in problem solving. Many educators assume that the mistakes are negative thing to avoid in learning mathematics. Whereas, errors is one of main factor in improving quality of learning, both for students and educators themselves. Educators who have awareness to correct learner errors will capable to improve quality of learning more quickly. Error analysis is one of way to understand cause of errors and repair it [8].

Errors can't be avoided by learners in learning mathematics. Errors relate with learner difficulties in learning mathematics [5]. Learner difficulties in constructing and solving mathematical problems are often reflected in learner errors [6]. This error should not be an obstacle for learners and even educators in achieving the goals of mathematics learning. Educators can understand how learners thinking process through errors [2]. The wrong answer may not necessarily result from the wrong thinking process, so there is an opportunity for learners to correct their errors through given reflection [10]. This is one type of pseudo-thinking process.
Pseudo-thinking can be considered in the context of problem solving and concept construction. The pseudothinking process is thinking process that produces "incorrect" answers in problem solving or concept construction [7]. Pseudo-correct in problem solving occurs when learners answer correctly but process of thinking learners is incorrect. Pseudo-wrong in problem solving occurs when learners answer wrongly but learners are able to explain the reason properly. Pseudo-true in concept construction occurs when learners are seen writing concept correctly even though their understanding of concept is wrong. Pseudo-wrong in concept construction occurs when learners write the concept wrongly, whereas their understanding of the concept is correct. The focus of the problem in this study is that students who experience pseudo- wrong thinking in solving geometric problems. Problem solving refers to Polya's problem-solving step, that is understanding the problem, planning, implementing the planning, and re-examining [1].

\section{METHOD}

This type of research is descriptive qualitative research. This study aim is to describe errors and repair errors in students who experienced pseudo-wrong in solving geometry problems. The problem solving given in this study is related to the angle. In solving geometry problem students are not only required to understand and apply the concept of the angle but also connect with the concept of triangle, circle, trigonometry and Pythagorean Theorem. The subject of the study is a student of Mathematics Education course which has taken the course of Euclid Geometry. The subjects of the study were selected from 3 different classes of Euclid geometry. From each class selected 1 student who experienced pseudo-wrong thinking in solving the geometry problem. Student from the first class called S1, from second class called S2, and from third class called S3.

Data collection was obtained through problem solving geometry test and interview. Tests aims to determine the errors of students in solving geometry problems. Students are asked to give the answer unraveled from the given problem. The given problem is as follows. An architect designed a park with an entrance defined as point $C$ and a circular park with center $O$ as shown in the picture below. The architect planned to connect three points around the park, that is $\mathrm{A}, \mathrm{B}$ and $\mathrm{D}$ and the park entrance, that is $\mathrm{C}$ with the path so that the path $\overline{C A}$ and $\overline{C B}$ are the tangent of the circular park. The architect also designs a path $\overline{D O E C}$ as passage passes through the center of the park such that $m \overrightarrow{A D B}: m \overline{A E B}=3: 2, m \overline{B C}=$ 
$60 \mathrm{~m}$ and $m \overline{E C}=43,6 \mathrm{~m}$. Determine the angle measure formed between the path $\overline{C A}$ and $\overline{C B}$.

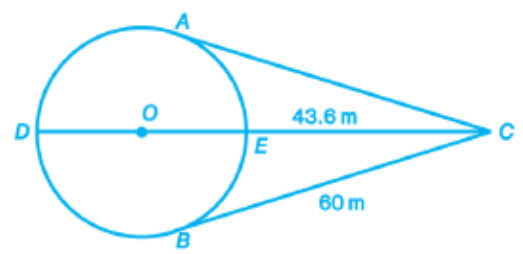

Fig. 1. Geometry problem relate to angle

Students who have errors in solving problems then asked to think out loud through detail interview. The aim interview is to understand deeply about why errors can happen, what concepts and procedures are used, why use the concepts and procedures, and how the stages of the problem solving. Interview also aims to find out whether the students include pseudo-wrong that is student who can still provide justification although the answer is wrong. This is obtained when students are asked to think loud, which in this case means the students are asked to explain process of solving geometry problem from start to finish. Based on the explanation, researcher define how repair student errors so that students are able to solve problem correctly.

\section{RESULTS AND DISCUSSION}

Solving this geometry problem involves concepts and procedures relating to angles, triangles, circles, trigonometry and Pythagorean Theorem. The concept and problem solving flow are presented in Figure 2. Student errors in problem solving are reviewed in four stages: understanding problems, planning, implementing plans and re-examining. Repaired errors are adjusted to problem structure in Figure 2 through the assimilation and accommodation stages.

A. Error Description and Repair Errors in Geometry Problem Solving in S1

Description of error S1 is reviewed from four Polya steps, namely understand the problem, make plans, implement plans, and re-examine. S1 is able to understand the problem well, that is determine measure of angle formed between the path $\overline{C A}$ and $\overline{C B}$. S1 is also able to make a good settlement plan that is to determine measure of $\angle A C B$ that can be found by stating $m \angle A C B=m \angle A C O+m \angle B C O$.

Furthermore, in implementing plans $\mathrm{S} 1$ have some errors. The first error, $\mathrm{S} 1$ does not express $m \overline{O C}$ as $m \overline{O C}=r+$ $m \overline{E C}=r+43,6$. S1 assumes that $m \overline{O C}=4,36$ without consider $\overline{O E}$ as the radius of the circle (r). This first error affect the second error, that is, when applying a trigonometric comparison with the sine rule in step $c_{7}$. Furthermore, in the last step, that is $c_{16}, \mathrm{~S} 1$ unable to justify why to determine measure of $\angle A C B$ can be obtained by multiplying twice measure of $\angle A C O$. This is related to the concept of triangle congruence that should be understood by students. In the reexamination stage, S1 already have awareness of the importance of re-examining the problem solving steps that have been done previously.
Based on above descriptions, S1 experienced pseudo thinking. Students who think pseudo have the opportunity to repair their errors. Therefore, the researcher gives an error correction by considering several things. First, $\mathrm{S} 1$ is asked to pay attention to the relationship between $\overline{O C}$ with radius of circle. Second, recalculate the result of trigonometric ratio with the sine rule in step $c_{7}$. Third, recall concept of triangle congruence to determine that $m \angle A C O=m \angle B C O$.

\section{B. Error Description and Repair Errors in Geometry Problem Solving in $\mathrm{S} 2$}

The description of the $\mathrm{S} 2$ error is also reviewed from four Polya's steps. S2 is able to understand the problem well, that is determine measure of angle formed between the path $\overline{C A}$ and $\overline{C B} . \mathrm{S} 1$ is also able to make a good settlement plan that is to determine measure of $\angle A C B$ that can be found by stating $m \angle A C B=m \angle A C O+m \angle B C O$. Furthermore, in implementing plans $\mathrm{S} 1$ have some errors.

The first error, S2 connect the points $A$ and $B$ such that $\overline{A B}$ across $\overline{O C}$ at point $P$ and obtain $\triangle A P C$ and $\triangle B P C$. This error occurs because student failure to understand that the triangle should be formed are $\triangle A O C$ and $\triangle B O C$ which is right triangle by connecting each point $A$ and $B$ with point $O$. Whereas, S2 understand that by connecting the two points will formed radius $\overline{O A}$ and $\overline{O B}$ which will be very helpful in solving this geometry problem. This first error resulted second error in applying Pythagorean theorem and trigonometric ratios in steps $c_{6}$ and $c_{7}$.

Furthermore, in the last step, that is $c_{16}, \mathrm{~S} 2$ is unable to justify why to determine measure of $\angle A C B$ can be obtained by multiplying twice measure of $\angle A C O . \mathrm{S} 2$ is able to mention the concept of triangle congruence but can't determine what postulate that should be used. In the re-examination stage, S2 already have awareness of the importance of re-examining the problem solving steps that have been done previously.

Based on above e descriptions, S2 also experienced pseudo thinking. Therefore, the researcher gives the treatment by considering several things to give an opportunity for S2 to repair errors. First, the S2 is asked to look again at the relationship of the radius of the circle and the triangles formed. Second, recalculate the results of the application of Pythagorean theorem in step $c_{6}$ and trigonometric ratio with the sine rules in step $c_{7}$. Third, recall concept of triangle congruence to determine that $m \angle A C O=m \angle B C O$.

\section{Error Description and Repair Errors in Geometry Problem Solving in S3}

The description of the $\mathrm{S} 3$ error is also reviewed from four Polya's steps. S3 is able to understand the problem well, that is to determine measure of angle formed between the path $\overline{C A}$ and $\overline{C B}$. S3 is also able to make a good settlement plan that is to determine measure of $\angle A C B$ that can be found by stating $m \angle A C B=m \angle A C O+m \angle B C O$. Furthermore, in implementing plans S1 have some errors. S2 and S3 errors are similar, but causes of error are different. In the first step of the implementation of the plan, S3 focus on the known statement that is ratio of $m \widehat{A D B}: m \widehat{A E B}=3: 2$. This statement is even accompanied by good justifications to be 
applied in problem solving, but instead makes S3 do many error in determining its further steps. S3, similar to $\mathrm{S} 2$, fail to understand that the triangle should be formed are $\triangle A O C$ and $\triangle B O C$ which is right triangle by connecting point $A$ and $B$ respectively with point $\mathrm{O}$. Whereas, $\mathrm{S} 3$ already understand that by connecting both points it will form the radius $\overline{O A}$ and $\overline{O B}$ which will be very helpful in solving this problem.

That error resulted next error in applying Pythagorean theorem and trigonometric ratios in steps $c_{6}$ and $c_{7}$. Furthermore, in the last step, that is $c_{16}, \mathrm{~S} 3$ is unable to justify why to determine measure of $\angle A C B$ can be obtained by multiplying twice measure of $\angle A C O$. Whereas this is related to the concept of triangle congruence that students should understand. At the re-examination stage, S3 already has the awareness of the importance of checking back on the previous troubleshooting steps.

Based on the above exposure, the S3 also experiences pseudo thinking. Therefore, the researcher provides the treatment by considering several things to give the S3 an opportunity to repair errors and solve problem correctly. The repair steps given on S3 are similar as the repair steps given in S2. First, the S3 is required to pay attention to the relationship between radius of circle and triangles formed. Second, recalculate the results of the application of Pythagorean theorem in step $c_{6}$ and trigonometric ratio with the sine rules in step $c_{7}$. Third, recall concept of triangle congruence to determine that $m \angle A C O=m \angle B C O$.

TABLE I. STEPS ON SOLVING GEOMETRY PROBLEM

\begin{tabular}{|c|c|c|}
\hline Steps of Polya & Code & Description \\
\hline \multirow[t]{5}{*}{ Understand problem } & $m$ & Understand main problem that is determine angle measure of $\angle A C B$ \\
\hline & $a_{1}$ & Understand given statement that is $m \overline{E C}=43,6 \mathrm{~m}$ \\
\hline & $a_{2}$ & Understand given statement that is $m \overline{B C}=60 \mathrm{~m}$ \\
\hline & $a_{3}$ & Understand given statement from picture that $\overline{A C}$ and $\overline{B C}$ are tangent line of circle drawn from point $C$ \\
\hline & $a_{4}$ & Understand given statement from picture that $\overline{O A}, \overline{O B}$, dan $\overline{O E}$ are radius of circle \\
\hline Make a plan & $b_{1}$ & $\begin{array}{l}\text { Plan that before determine measure of } \angle A C B \text { it should be determine measure of } \angle A C O \text { and } \angle B C O \\
\text { such that } m \angle A C B=m \angle A C O+m \angle B C O\end{array}$ \\
\hline \multirow[t]{15}{*}{ Implement plan } & $c_{1}$ & Determine that $\overline{A C} \cong \overline{B C}$ based on $a_{3}$ \\
\hline & $c_{2}$ & Determine that $\angle C A O \& \angle C B O$ are right angle based on $a_{3}$ dan $a_{4}$ \\
\hline & $c_{3}$ & Determine that $\triangle C A O \& \triangle C B O$ are right triangle based on $c_{2}$ \\
\hline & $c_{4}$ & Determine that $m \overline{O A}=m \overline{O B}=m \overline{O E}=r$ based on $a_{4}$ \\
\hline & $c_{5}$ & Determine that $m \overline{O C}=r+m \overline{E C}=r+43,6$ based on $a_{1}$ and $c_{4}$ \\
\hline & $c_{6}$ & $\begin{array}{l}\text { Determine } r \text { by applying Pythagorean theorem }(m \overline{O C})^{2}=(m \overline{O A})^{2}+(m \overline{A C})^{2} \text { or } \\
(m \overline{O C})^{2}=(m \overline{O B})^{2}+(m \overline{B C})^{2} \text { based on } a_{2}, c_{2}, c_{3} \text { dan } c_{4}\end{array}$ \\
\hline & $c_{7}$ & Apply trigonometric ratios to determine $\sin \angle A C O, \cos \angle A C O$ or $\tan \angle A C O$ based on $c_{3}, c_{5}$ and $c_{6}$ \\
\hline & $c_{8}$ & Determine that measure of $\angle A C O=18^{\circ}$ based on $c_{7}$ \\
\hline & $c_{9}$ & Determine that $\angle C A O \cong \angle C B O$ based on $c_{2}$ \\
\hline & $c_{10}$ & Determine that $\overline{O A} \cong \overline{O B}$ based on $c_{4}$ \\
\hline & $c_{11}$ & Determine that $\overline{O C} \cong$ based on reflevtice property of line segment congruence \\
\hline & $c_{12}$ & Apply SAS (side-angle-side) or SSS (side-side-side) theorem based on $c_{1}, c_{9}, c_{10}$ dan $c_{11}$ \\
\hline & $c_{13}$ & Determine congruent triagle that is $\triangle C A O \cong \triangle C B O$ based on $c_{12}$ \\
\hline & $c_{14}$ & Determine that $m \angle A C O=m \angle B C O$ based on $c_{13}$ \\
\hline & $c_{15}$ & Determine that $m \angle A C B=2 \times 18^{\circ}=36^{\circ}$ based on $b_{1}, c_{8}$ and $c_{14}$ \\
\hline Re-examine & - & Re-examine steps on problem solving \\
\hline
\end{tabular}




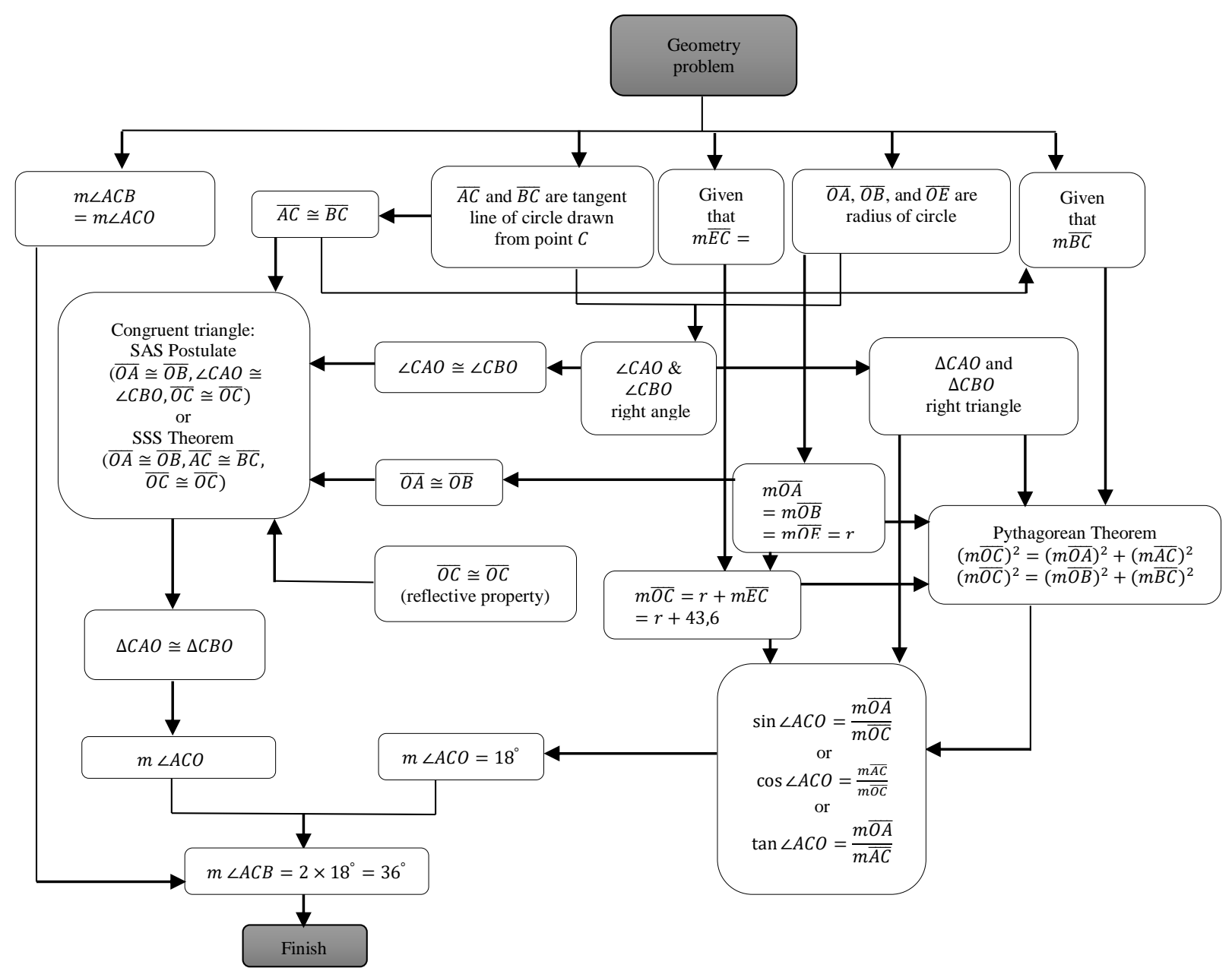

Fig. 2. Geometry problem structure

Steps of repair errors given to three research subjects, consider to process of assimilation and accommodation in students thinking process. Assimilation is process of integrating new stimulus into established schemes, while accommodation is a process of integrating new stimulus through the formation of new schemes to adapt stimulus received [2], [10]. This process of assimilation and accommodation involves prior knowledge that students already understand. Students are required to be able to connect the prior knowledge they already have with concept of problem solving. The ability to

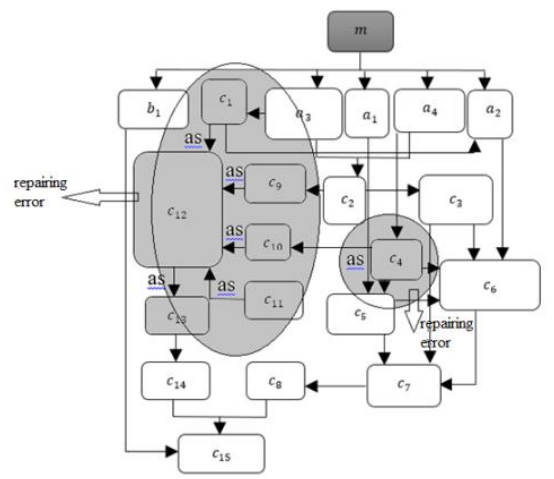

Fig. 3. Repairing error of S1 connect between knowledge is one of the capabilities students should have in mathematics learning [9]. The process of assimilation and accommodation is a process of adaptation of a person to a problem [10]. Assimilation and accommodation processes need to be taken into account in restructuring thinking process. In the restructuring of thinking process, treatment is required that ensures that repaired thinking process is correct [11]. These considerations may serve as suggestions for further studies.

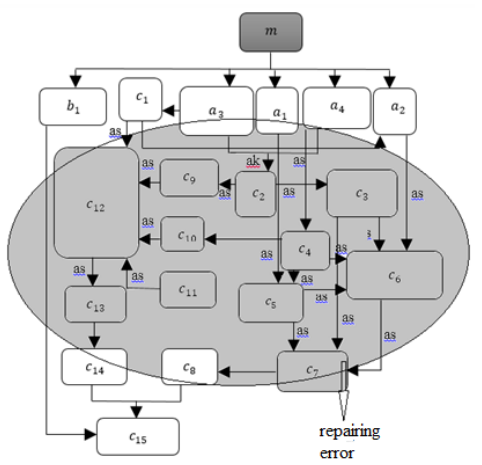

Fig. 4. Repairing error of S2 and S3 


\section{CONCLUSION}

Pseudo thinking students make errors in understanding problem and implementing plan. Errors that occurs are misunderstanding of measure of line segment, failure to understand that triangles should be formed $\triangle A O C$ and $\triangle B O C$ that is a right triangle, error in applying Pythagorean theorem and the trigonometric ratios, and unable to apply triangle congruence to justify congruence of measure of two angles. Repair errors is done by implementing assimilation and accommodation process. Both of these processes involve the student's prior knowledge about concept of triangle, circle, trigonometry and Pythagorean theorem in solving problems. Through this improvement, students are able to solve problem of geometry correctly.

\section{REFERENCES}

[1] Hähkiöniemi, M., Leppäaho, H. \& Francisco, J. Proceeding from the $13^{\text {th }}$ ProMath Conference: Model for Teacher Assisted Technology Enriched Open Problem Solving, Umeå, UMERC, 2012.

[2] Ingram, J., Baldry, F. \& Pitt, A, Proceedings on Eight Congress of the European Society for Research in Mathematic Education: The influence of how teachers interactionaliiy manage mathematical mistakes on the mathematics that student experience. Antalya, Turki, 2013.

[3] Irpan, S., "Proses Terjadinya Kesalahan dalam Penalaran Proporsional Berdasarkan Kerangka Kerja Asimilasi dan Akomodasi," Beta, 2010.

[4] Johnson \& Alibali, Conceptual and Procedural Knowledge of Mathematics: Does One Lead to the Other," Journal of Educational Psychology, vol. 91, no. 1, pp. 175-189, 1999.

[5] Sakif, S., Subanji \& Sisworo, Proceeding at International Seminar on Innovation in Mathematics and Mthematics Education 1st ISIM-MED: Defragmenting of Thinking Process Through Cognitive Mapping to Fix Student's Error in Solving the Problem of Algebra, Yogyakarta, 2014.

[6] Subanji \& Nusantara, T, "Karakterisasi Kesalahan Berpikir Siswa Dalam Mengonstruksi Konsep Matematika," Jurnal Ilmu Pendidikan, 2013.

[7] Subanji \& Nusantara, T, "Thinking Process of Pseudo Construction in Mathematics Concepts," International Education Studies, vol. 9, no. 2, pp.17-31, 2016.

[8] Sulistyorini, Yunis, "Analisis Kesalahan dan Scaffolding dalam Penyelesaian Persamaan Differensial," Kalamatika, 2017

[9] NCTM, Principle and Standards for School Mathematics. Reston: Virginia, 2000.

[10] Wibawa, Kadek Adi, "Defragmenting Struktur Berpikir Pseudo dalam Memecahkan Masalah Matematika". Yogyakarta: Deepublish, 2016.

[11] Wibawa, K.D., Nusantara, T., Subanji \& Parta, I. N., "Fragmentation of Thinking Structure's Students to Solving the Problem of Application Definite Integral in Area," International Education Studies, vol. 10, no. 5, pp.48-60, 2017. 